Research Article

\title{
Characteristics of Stable Isotopes in Precipitation and Their Moisture Sources in the Guanling Region, Guizhou Province
}

\author{
Jialu Wang $\left(\mathbb{D},{ }^{1,2}\right.$ Weijie Li $\mathbb{D}^{2},{ }^{2}$ Yong Wang $\mathbb{D}^{2},{ }^{2}$ Jiaojiao Zhang $\mathbb{D},{ }^{1}$ and Shizhen Xiao $\mathbb{i D}^{3}$ \\ ${ }^{1}$ School of Resources and Environmental Engineering, Anshun University, Anshun 561000, Guizhou, China \\ ${ }^{2}$ School of Geography Science, Southwest University, Chongqing 400715, China \\ ${ }^{3}$ School of Karst Science, Guizhou Normal University, Guiyang 550001, Guizhou, China
}

Correspondence should be addressed to Jialu Wang; wangj1226@126.com and Yong Wang; 190966549@qq.com

Received 20 February 2021; Revised 17 March 2021; Accepted 25 March 2021; Published 15 April 2021

Academic Editor: $\mathrm{Hu} \mathrm{Li}$

Copyright (c) 2021 Jialu Wang et al. This is an open access article distributed under the Creative Commons Attribution License, which permits unrestricted use, distribution, and reproduction in any medium, provided the original work is properly cited.

Environmental prediction is one of the crucial means for social sustainable development. Based on the continuous sampling of atmospheric precipitation in Guanling County, Guizhou Province, China, from March 2016 to February 2017, and combining the reanalyzed data of the National Centre for Environmental Prediction/National Centre for Atmospheric Research with the Hybrid Single-Particle Lagrangian Integrated Trajectory model, this paper analyzed the variations of $\delta^{2} \mathrm{H}$ and $\delta^{18} \mathrm{O}$ in precipitation at the synoptic scale in the Guanling region. The results showed that the variations of $\delta^{2} \mathrm{H}, \delta^{18} \mathrm{O}$, and $d$-excess values in precipitation exhibited remarkable seasonal variability. The stable isotopic values in precipitation in the winter half-year were higher than those in the summer half-year. The meteoric water line of the winter half-year was close to the annual meteoric water line. The results showed that there was more than one fundamental source of moisture. It was affected by the winter monsoon period, which is longer than the summer monsoon period, so the local evaporation of water vapor participating in the water circulation had a greater impact. With the increase of precipitation, the intercept and slope of the meteoric water line gradually decreased, which indicated that the secondary evaporation was weak under the effect of stable isotope subcloud cluster. The correlations of precipitation $\delta^{18} \mathrm{O}$ with temperature $T$ and precipitation $P$ vary with time scales. As the time scale decreased, the correlation between $\delta^{18} \mathrm{O}$ and the temperature and precipitation improved. When $P \leq 5 \mathrm{~mm}$ and $10^{\circ} \mathrm{C}<T \leq 30^{\circ} \mathrm{C}$, the most sensitive changes in stable isotopes were observed. In the study area, the backward trajectory model showed that the moisture in the winter half of the year was mainly from the transportation of the westerlies wind, replenishment, and local reevaporation of near-source ocean water, while the water in the summer half of the year mainly came from the transportation of water from the ocean at low latitudes.

\section{Introduction}

Precipitation is the most active factor in the exchange of matter and energy between the atmosphere and the hydrosphere, and it is also an important part of the water cycle. The composition of stable isotope in precipitation is closely related to the meteorological process of precipitation, the initial state of the water vapor source region, and the situation of large-scale circulation. The monitoring of precipitations $\delta^{2} \mathrm{H}$ and $\delta^{18} \mathrm{O}$ will provide fundamental data for the study of water cycles in present and past climates using stable isotope techniques [1].

The study of stable isotopes in precipitation began in the early 1950s. Since 1961, the International Atomic Energy
Agency (IAEA) and the World Meteorological Organization (WMO) jointly initiated the Global Network for Isotopes in Precipitation (GNIP). So far, more than 800 precipitation sampling stations have been established worldwide, their purpose is to analyze the change in time and space and to identify global and local atmospheric circulation patterns and the water cycle mechanism [2]. The study of stable isotopes in the water cycle started relatively late in China, beginning with the scientific expedition to Mount Everest in 1966 [3]. The GNIP in China gradually began to establish multiple monitoring stations for a long time, but it is still difficult to meet the needs of scientific research. In 2004, China established the Chinese Network of Isotopes in Precipitation (CHNIP) under the support of various field 
stations in the Chinese Ecosystem Research Network (CERN) [4].

In recent decades, the research on stable isotopes of atmospheric precipitation has made remarkable progress. The results show that $\delta^{2} \mathrm{H}$ and $\delta^{18} \mathrm{O}$ have distinct spatial and temporal distributions in China's precipitation. Because of China's geographical location and diverse climatic conditions, $\delta^{18} \mathrm{O}$ has different regional distributions in precipitation. The water vapor sources of precipitation in the southwest monsoon region of China are very complex, and the different water vapor sources from the Western Pacific Ocean, South China Sea, Bay of Bengal, Indian Ocean, Arabian Sea, and transequator strongly affect the precipitation in the southwest monsoon region of China [5]. Zhang et al. conducted an in-depth study on stable isotopes of precipitation over a large spatial scale in southwest China [6]. The characteristics of stable isotope variation of precipitation in southwest China are analyzed from synoptic, seasonal, and interannual scales. The study found that the changes in precipitation $\delta^{2} \mathrm{H}$ and $\delta^{18} \mathrm{O}$ in this area have obvious amount effects, humidity effects, and antitemperature effects, and the $d$-excess values in precipitation showed significant seasonal differences. Therefore, it is necessary to expand the precipitation isotope research in Guizhou area to increase the isotope data in this area and conduct a comprehensive and in-depth study of the southwest monsoon region of China.

Therefore, this paper analyzed the meteorological data and stable isotope data of precipitation samples in the hydrological years from March 2016 to February 2017 in Guanling, Guizhou Province. Through the propagation path of the model results, combined with the precipitation of the Hybrid Single-Particle Lagrangian Integrated Trajectory (HYSPLIT) into the air, the formation of the regional precipitation water vapor source, the water cycle area, and the palaeoclimate research are discussed, provide a scientific basis for follow-up research.

\section{Materials and Methods}

2.1. Overview of the Study Area. Guanling County is located in the southwest of Guizhou Province, between $25^{\circ} 34^{\prime}-26^{\circ} 05^{\prime} \mathrm{N}$ and $105^{\circ} 15^{\prime}-105^{\circ} 49^{\prime} \mathrm{E}$, with an area of $1,466 \mathrm{~km}^{2}$. The altitude drops from $1,850 \mathrm{~m}$ to $370 \mathrm{~m}$, an absolute difference of $1,480 \mathrm{~m}$. More mountains are less flat. Karst landform development accounts for more than $80 \%$ of the county's land area [7]. The Guanling region is a typical subtropical monsoon humid climate zone, and the sources of water vapor and the influencing factors of precipitation are complex. According to the meteorological data in this region, the average annual rainfall is 1 , $268 \mathrm{~mm}$, and the average annual temperature is $16.2^{\circ} \mathrm{C}$. The dry and wet seasons in the study area are obvious. The rainy season is from May to October, and the precipitation accounts for more than $80 \%[8]$.

2.2. Collection and Analysis of Precipitation Samples. This study was conducted from March 2016 to February 2017 in Naduo Village, Guanling County, $13 \mathrm{~km}$ away from the county seat of Guanling, on the rooftop of a farmer's bungalow $\left(105^{\circ} 35^{\prime} \mathrm{E}, 25^{\circ} 49^{\prime} \mathrm{N}\right)$. A dry and clean atmospheric precipitation collector is placed in the open-air environment. The collector device is $25 \mathrm{~cm}$ away from the top layer and is hardly affected by ground dust. A precipitation observation is conducted at 8 am and 8 pm every day. Each time precipitation samples are collected, the precleaned polyethylene bottle should be moistened with precipitation samples, and then the collected precipitation should be put into the sample bottle. After tightening the cap, the bottle mouth shall be sealed with sealing film to prevent isotope fractionation caused by evaporation.

Water samples were analyzed using the Los Gatos Research (LGR) Company of the United States research and development of liquid water isotope analyzer (DLT-100 type: 908-0008) measurement of oxygen precipitation and deuterium ratios; testing accuracy is $\delta^{18} \mathrm{O} \leq 0.1 \%, \delta^{2} \mathrm{H} \leq 0.5 \%$. Among the water samples tested and analyzed, we selected the different isotope ratio of the IAEA prototype as a reference and selected the sample value relative to the average of the ViennaStandard Mean Ocean Water (V-SMOW). In this experiment, the working samples LGR3A, LGR4A, and LGR5A produced by American Company LICOR were selected as reference samples to measure stable isotopes in the precipitation in the Guanling area (see Table 1). In the sample test sequence, a working standard sample is inserted every three samples, and each sample is measured six times. The results of the first two measurements are automatically deleted, and the last four measurements are saved to remove the memory effect $[9,10]$.

In the test analysis of the samples, standard samples with different isotope ratios from the IAEA are used for reference. The standard sample values are expressed by the thousandths of the V-SMOW.

2.3. Introduction to the Backward Trajectory Tracking Model. The HYSPLIT model is a professional model with an Eulerian-Lagrangian module calculation jointly developed by the National Oceanic and Atmospheric Administration (NOAA) Air Resources Laboratory and the Australian Bureau of Meteorology. It is used to analyze the propagation and diffusion path of atmospheric pollutants.

It is used to analyze the propagation and diffusion path of atmospheric pollutants. The model can be used to track the migration path of the particles carried by the flow and to predict the wind field situation in real time. The model includes a forward trajectory tracking module and a backward trajectory tracking module. This paper adopts the backward trajectory tracking module of this model. Combined with the meteorological data reanalyzed by the $\mathrm{Na}$ tional Centre for Environmental Prediction/National Centre for Atmospheric Research (NCEP/NCAR), the horizontal resolution was $2.5^{\circ} \times 2.5^{\circ}$, and the vertical shared trajectory mode was used to backward derive the particle trajectory for $166 \mathrm{~h}$.

\section{Results and Discussion}

3.1. Characteristics of Stable Isotopic Changes in Atmospheric Precipitation. The seasonal variation characteristics of daily precipitation are not obvious in the study area from March 
TABLE 1: Standard samples of different specifications (\%o).

\begin{tabular}{lcc}
\hline Sample description & $\delta^{18} \mathrm{O}(\mathrm{V}-\mathrm{SMOW})$ & $\delta^{2} \mathrm{H}(\mathrm{V}-\mathrm{SMOW})$ \\
\hline LGR3A & -13.1 & -96.4 \\
LGR4A & -7.7 & -51.0 \\
LGR5A & -2.8 & -9.5 \\
\hline
\end{tabular}

2016 to February 2017. During the observation period, the annual precipitation was $1,100 \mathrm{~mm}$ and the average temperature was $16.9^{\circ} \mathrm{C}$. From May to October, the annual precipitation accounted for about $59.7 \%$. Half a year in winter, the annual precipitation accounted for about $40.3 \%$. The annual distribution of precipitation is relatively average. According to observations, small precipitation events $(P \leq 10 \mathrm{~mm})$ accounted for $79.1 \%$ of the total precipitation events, while heavy precipitation events $(P>10 \mathrm{~mm})$ accounted for $20.9 \%$. Among them, there were six times in total above $30 \mathrm{~mm}$, namely, $54 \mathrm{~mm}$ from April 8 to 14 , $70 \mathrm{~mm}$ from May 23 to $27,65 \mathrm{~mm}$ from August 3 to 5 , $37 \mathrm{~mm}$ from August 23 to 26, $34 \mathrm{~mm}$ from October 28 to 29, and $51 \mathrm{~mm}$ from December 3 to 4 .

The values of $\delta^{2} \mathrm{H}$ in the precipitation in the area range from $-149.8 \%$ o to $25.9 \%$, with an average of $-43.92 \%$; the values of $\delta^{18} \mathrm{O}$ range from $-19.8 \%$ to $0.5 \%$, with an average of $-7.13 \%$. According to previous studies, the range of $\delta^{2} \mathrm{H}$ in the global precipitation is $-300 \%$ to $131 \%$, with an average of $-22 \%$. $\delta^{18} \mathrm{O}$ varies from $-54 \%$ to $31 \%$, and the average value is $-4 \%$ [11]. Zheng et al. found that the content of ${ }^{2} \mathrm{H}$ of atmospheric precipitation in China was $-190 \%$ o to $20 \%$, with an average of $-50 \%$. The content of ${ }^{18} \mathrm{O}$ is $-24 \%$ to $2 \%$, and the average value is $-8 \%$ [ [12]. In the Guanling region, it can be seen that the precipitations $\delta^{18} \mathrm{O}$ and $\delta^{2} \mathrm{H}$ are within the range of global and Chinese values, and the average precipitations $\delta^{18} \mathrm{O}$ and $\delta^{2} \mathrm{H}$ in the Guanling area are close to the average precipitation $\delta^{18} \mathrm{O}$ and $\delta^{2} \mathrm{H}$ in China. However, it is less than the global average of $\delta^{18} \mathrm{O}$ and $\delta^{2} \mathrm{H}$, indicating that the source of precipitation water vapor in the Guanling area has already experienced a certain degree of wind distillation before reaching the area.

Due to the different water vapor sources and evaporation conditions in this area, precipitations $\delta^{18} \mathrm{O}$ and $\delta^{2} \mathrm{H}$ have obvious seasonal changes in wet and dry seasons. In summer semiannual precipitation, the values of $\delta^{2} \mathrm{H}$ are between $-149.8 \%$ and $3.2 \%$, with an average of $-59.98 \%$; the value of $\delta^{18} \mathrm{O}$ is between $-19.8 \%$ and $0.5 \%$, with an average of $-8.70 \%$. In winter semiannual precipitation, the values of $\delta^{2} \mathrm{H}$ are between $-72.45 \%$ and $25.9 \%$, with an average of $-13.95 \%$; the values of $\delta^{18} \mathrm{O}$ are between $-13.74 \%$ and $-1.05 \%$, with an average of $-4.18 \%$. The water vapor in winter precipitation mainly comes from the transport of the Westerly and the supplement of local reevaporation of water vapor. With low humidity and strong evaporation, the enriched isotopes in the continental air mass might be "washed" very weak along the way, leading to the enrichment of heavy isotopes in precipitation. In summer, the precipitation mainly comes from the marine air mass transported by the southwest monsoon and the southeast monsoon. Due to the high humidity and weak evaporation of the Marine air mass, it constantly forms precipitation in the process of moving to the study area. The heavy isotopes in the air mass might be "washed," so the heavy isotopes in the precipitation are greatly depleted. At the same time, the change of precipitation of isotopes is also affected by water vapor condensation temperature, transportation mode of water vapor source, seasonal change of precipitation, temperature, humidity during precipitation, and so on [13].

In conclusion, the variations of $\delta^{18} \mathrm{O}$ and $\delta^{2} \mathrm{H}$ values in the precipitation in the Guanling region are generally enriched in the winter half-year and depleted in the summer half-year, relatively. The correlation between the values of $\delta^{2} \mathrm{H}$ and $\delta^{18} \mathrm{O}$ in the precipitation and amount of precipitation is not obvious. Precipitations $\delta^{18} \mathrm{O}$ and $\delta^{2} \mathrm{H}$ are significantly inversely related to the temperature in the region (see Figure 1), and the fundamental reason lies in the seasonal differences in the sources of precipitation moisture and evaporation conditions [14].

3.2. Meteoric Water Line. The linear relationship between $\delta^{2} \mathrm{H}$ and $\delta^{18} \mathrm{O}$ of precipitation isotopes is called the meteoric water line $(\mathrm{MWL})$, and the slope and intercept of the MWL are different under the influence of condensation temperature, water vapor source and transport mode, seasonal variation of precipitation, and air temperature and humidity during precipitation [15]. Craig [16] defined this relationship as the global meteoric water line (GMWL) with the equation $\delta^{2} \mathrm{H}=8 \delta^{18} \mathrm{O}+10$. Each local meteoric water line is controlled by regional climate factors including the origin of water vapor air mass, secondary evaporation during precipitation, and seasonal variation of precipitation, which affect deuterium surplus and slope [17].

Based on the analysis of precipitation stable isotope, the equation of the meteoric water line (of the whole year) in the study area is obtained using the least square method: $\delta^{2} \mathrm{H}=8.81 \delta^{18} \mathrm{O}+18.91 \quad\left(R^{2}=0.975, n=86\right) \quad$ (see Figure 2). Compared with the GMWL $\left(\delta^{2} \mathrm{H}=8 \delta^{18} \mathrm{O}+10\right)$ [16] and the MWL $\left(\delta^{2} \mathrm{H}=7.9 \delta^{18} \mathrm{O}+8.2\right)$ reported by Zheng et al. [12] in China, the slope and intercept of the MWL in the study area are larger, which may be influenced by temperature, evaporation, and other factors during the raindrop falling process [18]. The annual MWL in Guanling is similar to the MWL in Changsha $\left(\delta^{2} \mathrm{H}=8.74 \delta^{18} \mathrm{O}+15.46\right)[19]$, Fuzhou $\left(\delta^{2} \mathrm{H}=8.84 \delta^{18} \mathrm{O}+16.19\right)$ [19], and Yingtan $\left(\delta^{2} \mathrm{H}=8.61 \delta^{18} \mathrm{O}+18.34\right)$ [20], indicating that precipitation and monsoon types and sources of water vapor are similar in these areas, which are basically on the same water vapor channel.

The linear relationship between $\delta^{18} \mathrm{O}$ and $\delta^{2} \mathrm{H}$ in the half-yearly precipitation in winter and summer in the Guanling region is also different (see Figure 2). The MWL of half a year in summer is $\delta^{2} \mathrm{H}=8.23 \delta^{18} \mathrm{O}+11.67\left(R^{2}=0.983\right.$, $n=56$ ), and the MWL of half a year in winter is $\delta^{2} \mathrm{H}=8.79 \delta^{18} \mathrm{O}+22.84\left(R^{2}=0.955, n=30\right)$. Compared with the MWL in summer and in winter half a year, the slope and intercept of semiannual precipitation in winter are higher than those of semiannual precipitation in summer, which is related to the difference of dynamic fractionation processes caused by different water vapor sources. The MWL of summer semiannual atmospheric precipitation is close to 


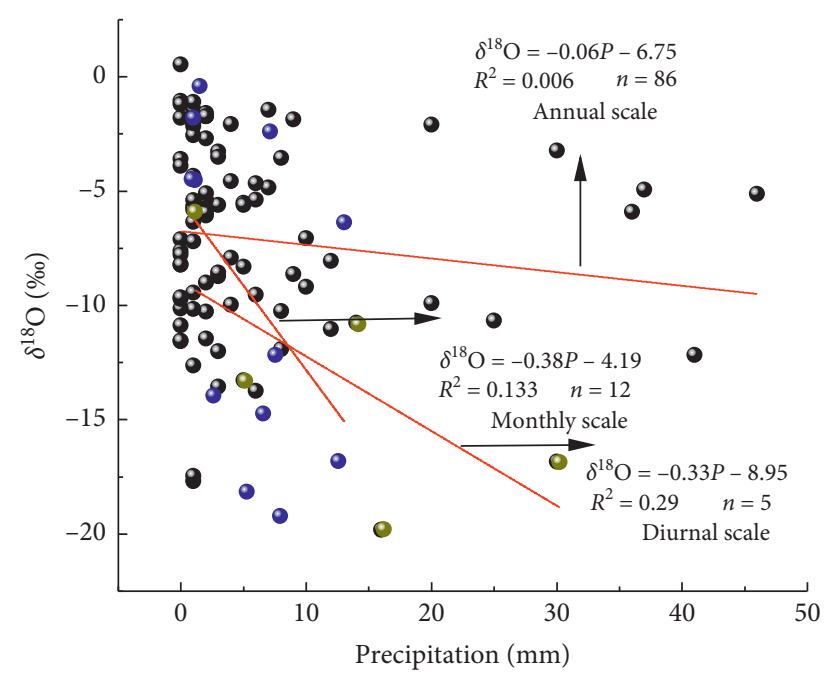

(a)

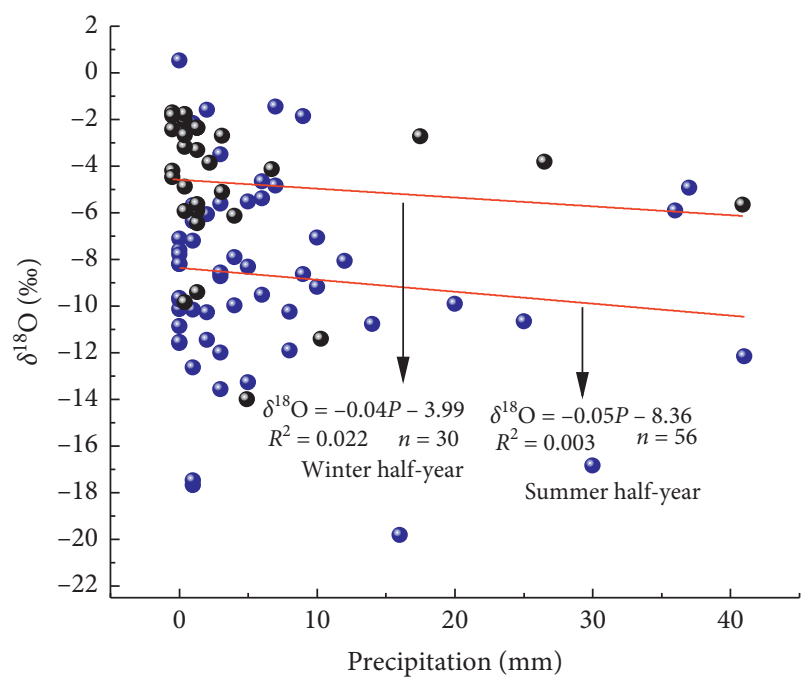

(c)

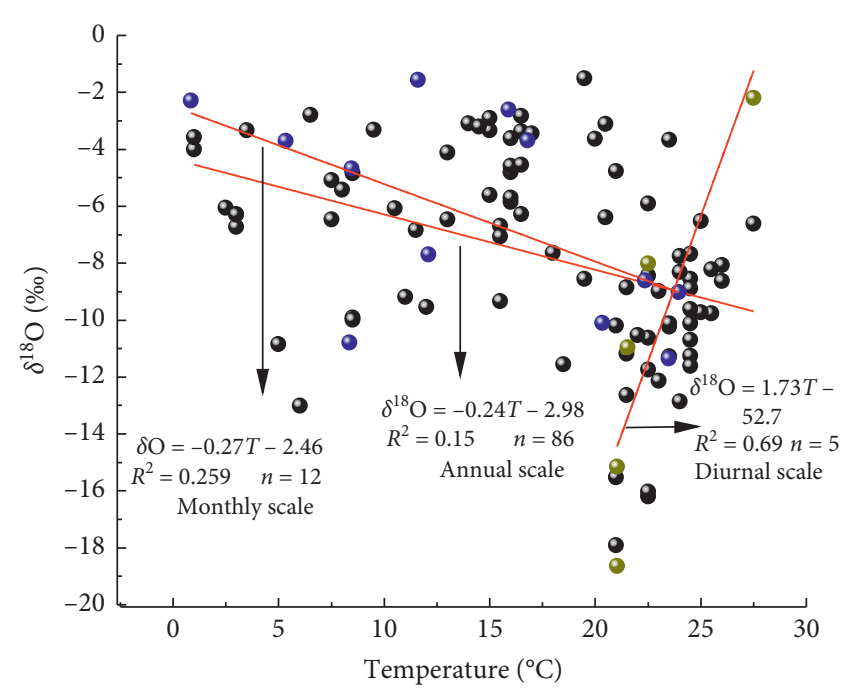

(b)

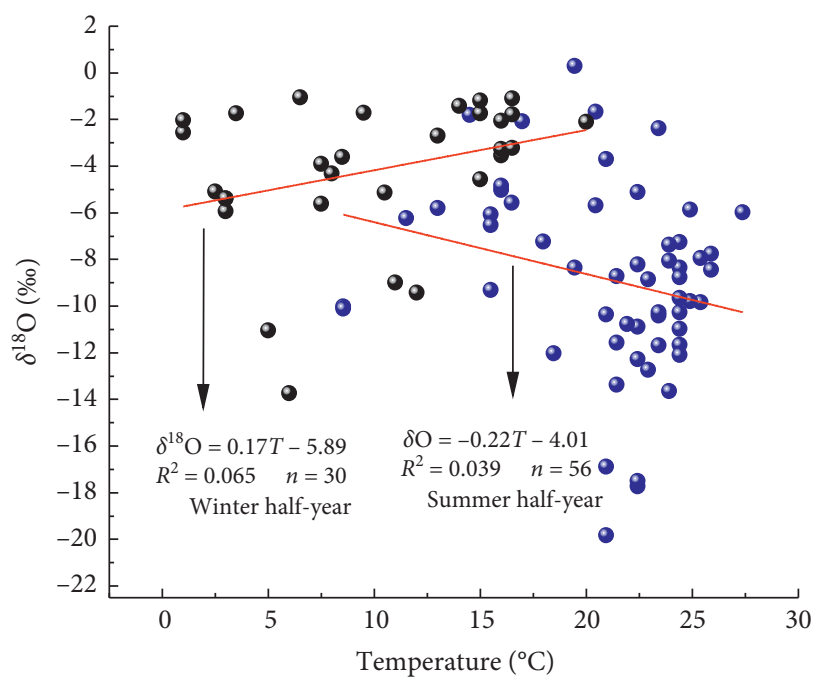

(d)

FIgURE 1: Correlations between $\delta^{18} \mathrm{O}$ in precipitation and meteorological parameters in the Guanling region.

GMWL, indicating that water vapor in the summer semiannual precipitation originates from low-latitude oceanic air mass. Compared with the MWL of the whole year, the MWL of half a year in winter is closer to that of the whole year than that of half a year in summer, indicating that the annual MWL of the Guanling region is greatly affected by water vapor sources in winter.

\subsection{Correlation between Precipitation Stable Isotopes and} Meteorological Factors: Secondary Evaporation under Clouds. There is a correlation between the hydrogen and oxygen stable isotopic composition of meteoric precipitation and various meteorological factors. However, among the many meteorological factors that affect the variation of precipitation stable isotopes, the temperature effect and amount effect are particularly prominent. Dansgaard [21] found that there was a significant positive correlation between precipitation $\delta^{18} \mathrm{O}$ and temperature, which was defined as the temperature effect, while precipitation $\delta^{18} \mathrm{O}$ had an inverse correlation with the amount of precipitation, which was defined as the "amount effect."

Temperature restricts condensation and evaporation and affects stable isotope fractionation during precipitation. The lower the air temperature is, the higher the fractionation coefficient of stable isotopes in precipitation is and the lower $\delta^{18} \mathrm{O}$ in precipitation is [22]. Generally speaking, the temperature effect mainly appears in the middle and high latitudes, especially at the poles. The deeper into the interior of the continent goes, the higher the positive correlation between air temperature and the precipitation $\delta^{18} \mathrm{O}$ becomes [11]. According to the isotopic monitoring data of atmospheric precipitation in the Guanling area (see Figure 1), the time scale is divided into annual scale, winter half-year, summer half-year, monthly scale, and daily scale. And the correlation between daily average temperature and precipitation $\delta^{18} \mathrm{O}$ was analyzed. The correlation between $\delta^{18} \mathrm{O}$ and daily average temperature varies with different time scales. The correlation coefficients on the annual, monthly, and 


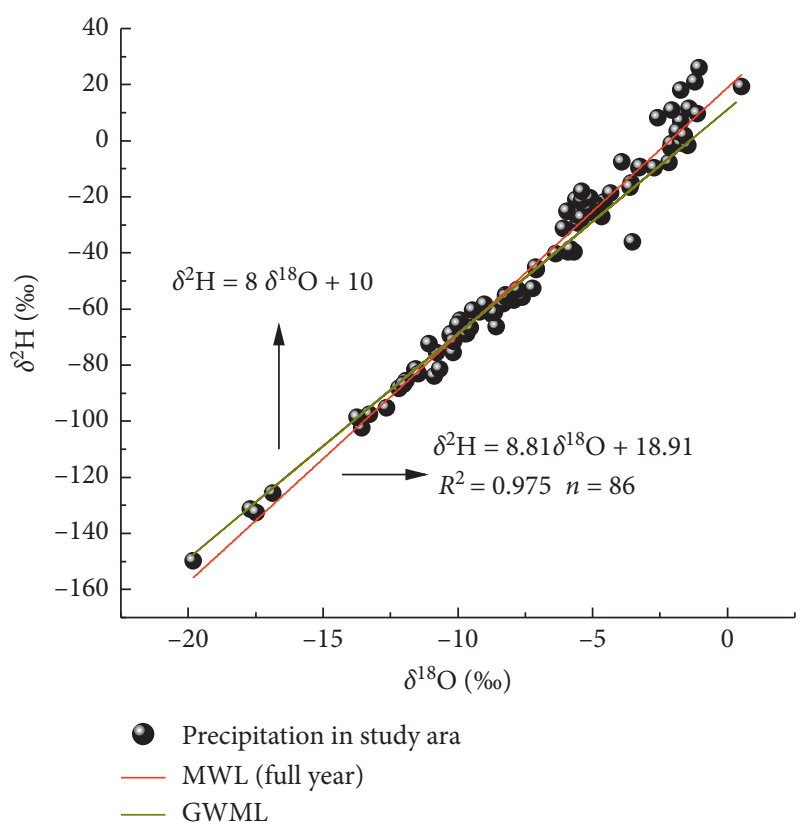

(a)

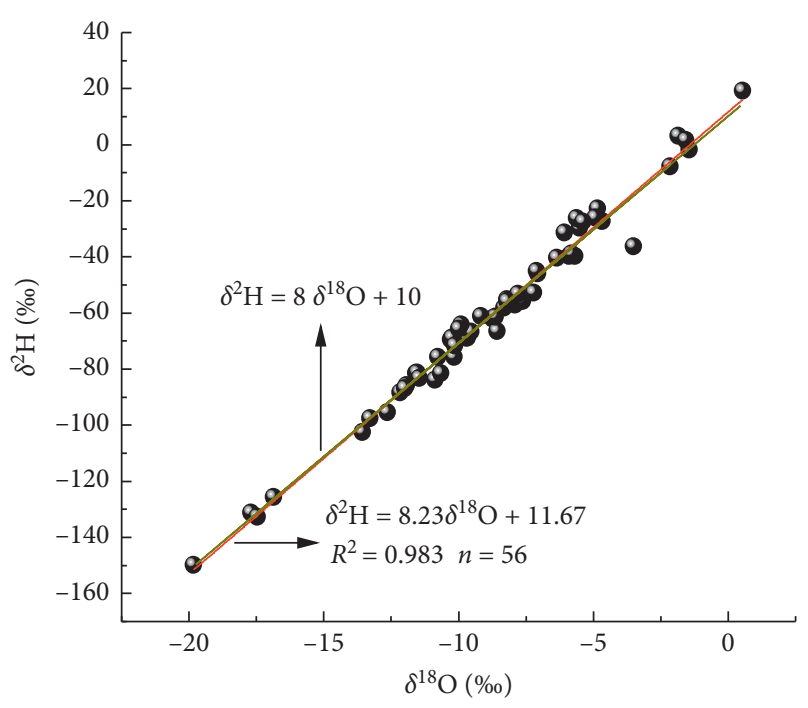

- Precipitation in study ara MWL (summer half-year) GWML

(b)

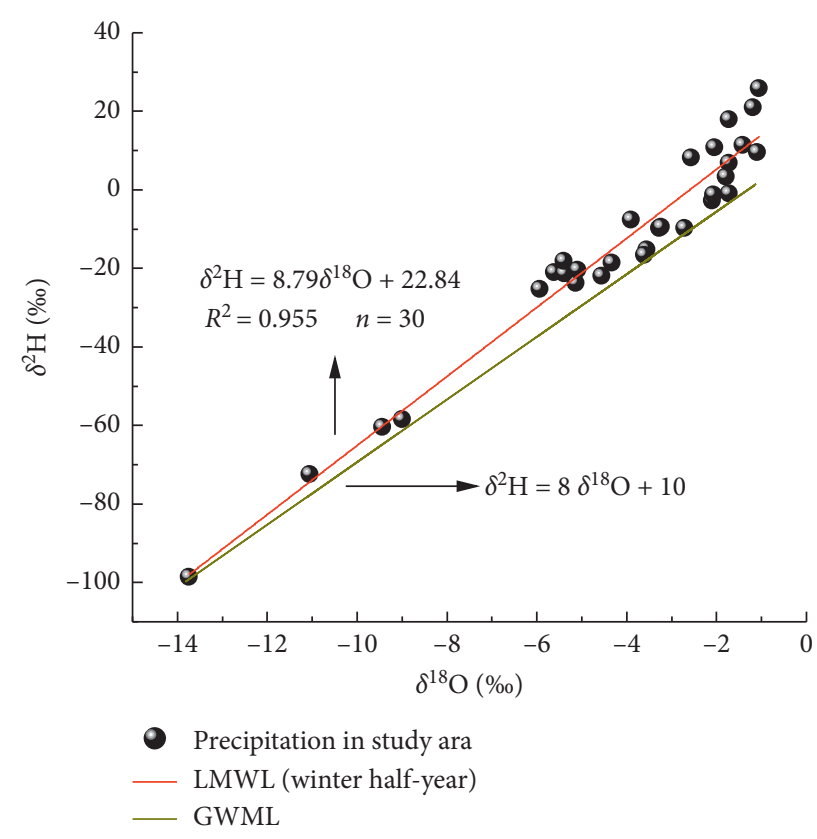

(c)

Figure 2: Equation of meteoric water line in the Guanling region.

daily scales are $0.15,0.26$, and 0.69 , respectively. The smaller the time scale, the better the correlation. Atmospheric precipitation $\delta^{18} \mathrm{O}$ is only positively correlated with the temperature on the daily scale and the half-year winter scale but has no significant positive correlation with temperature on other time scales. This phenomenon is common in the midlow latitudinal monsoon region, commonly known as the inverse temperature effect. This is mainly due to the greater influence of the monsoon climate on $\delta^{18} \mathrm{O}$ in the atmospheric precipitation. To some extent, the temperature effect is suppressed and masked by the monsoon climate, and the characteristic changes of stable isotopes on the synoptic scale and the half-year winter scale can more accurately reflect the changes of climatic and meteorological elements in the region.

The amount effect is related to the precipitation process of severe convective weather. The formation mechanism mainly depends on three processes of precipitation formation: evaporation conditions in the water vapor source region, water vapor transmission process, and condensation degree during precipitation [23]. The value of $\delta^{18} \mathrm{O}$ is low in the summer and autumn precipitation in the areas affected 
by the monsoon in China, while the value of $\delta^{18} \mathrm{O}$ is high in the spring and winter precipitation in south China, which is caused by not only the amount effect but also the influence of the monsoon [11]. Through the correlation analysis of daily precipitation and precipitation $\delta^{18} \mathrm{O}$, there is a negative correlation between precipitation $\delta^{18} \mathrm{O}$ and the amount of precipitation, namely, the amount effect. The difference in the time scale results in the difference in the correlation. The correlation coefficients of annual scale, monthly scale, and daily scale are $0.006,0.133$, and 0.29 , respectively. It can also be seen that the smaller the time scale was, the better the correlation between them would be. During August 3 to 5, the change of the values of atmospheric precipitation $\delta^{18} \mathrm{O}$ shows a V-shaped fluctuation, which may be caused by the heavy isotopes ${ }^{2} \mathrm{H}$ and ${ }^{18} \mathrm{O}$ condensing into raindrops in the process of rainfall. Therefore, $\delta^{18} \mathrm{O}$ tends to be enriched at the beginning of rainfall, and as the rainfall progresses, the heavy isotopes in the precipitation clouds are continuously "washed away," leading to the gradual depletion of rainfall $\delta^{18} \mathrm{O}$. In other words, $\delta^{18} \mathrm{O}$ decreases significantly with the extension of time during rainfall, showing a significant rainfall effect, while the fluctuation of $\delta^{18} \mathrm{O}$ during rainfall can be considered as the influence of local water vapor recycling [24].

In conclusion, the correlation between $\delta^{18} \mathrm{O}$ of precipitation and temperature and precipitation in the Guanling area varies with different time scales. The atmospheric precipitation $\delta^{18} \mathrm{O}$ is positively correlated with the temperature scale on the daily scale and the winter semiannual scale, while the other time scales are negatively correlated. At all time scales, precipitation $\delta^{18} \mathrm{O}$ shows an amount of effect with the amount of precipitation. Meanwhile, with the decrease of time scale, precipitation $\delta^{18} \mathrm{O}$ has a greater correlation with temperature and amount of precipitation. The inverse temperature effect of $\delta^{18} \mathrm{O}$ is higher than that of precipitation on the annual scale and monthly scale. The effects of temperature in winter and precipitation in summer are significant. The temperature effect and the amount effect work together on a daily scale.

To explore whether there is a secondary evaporation effect of stable isotopes of precipitation in the Guanling region, 86 precipitation samples were divided into four groups according to rainfall levels, and each rainfall level was divided into 2-3 groups according to temperature level by level. Slope, intercept, and correlation coefficient of the MWL equation under different rainfall levels were compared and analyzed (see Table 2).

According to research on the subcloud secondary evaporation effect of stable isotopes in precipitation in the Loess Plateau [25], Yangtze River Basin [26], Haihe River Basin [27], and Tengchong, Yunnan [11], with the increase of rainfall level, the slope and intercept of the MWL also increase. Raindrops in small rainfall events are more susceptible to secondary evaporation at the cloud bottom during the falling process, and dynamic fractionation is intensified, resulting in a significant decrease in the slope and intercept of MWL. For large rainfall events or continuous rainfall events, the atmosphere at the bottom of the cloud tends to be saturated, the influence of secondary evaporation on raindrop falling is weakened, and the slope and intercept of the MWL eventually increase correspondingly. The research results in the Guanling region show that as the rainfall level increases, the stable heavy isotopes gradually become depleted, and the slope and intercept of the MWL decrease, including the slope from 9.13\%o $(P \leq 1 \mathrm{~mm})$ to $8.08 \%$ o $(P>10 \mathrm{~mm})$ and the corresponding intercept from $21.42 \%$ to $11.31 \%$. The stable isotopes in the precipitation are less affected by the secondary evaporation effect of the cloud bottom. It can be found that, for the $P \leq 1 \mathrm{~mm}$ of rainfall events, the slope and intercept of the MWL are significantly greater than other rainfall levels, which may be caused by unbalanced secondary or multiple evaporation during raindrop falling. In the case of rainfall events for $P>10 \mathrm{~mm}$, the slope and intercept of the MWL are smaller than those of other rainfall classes. The reasons may be attributed to the fact that the raindrop is subjected to greatly unbalanced evaporation during the falling process, and the dynamic fractionation of stable isotopes is intensified, which results in the decrease of slope and intercept of the MWL.

When the temperature level of $P \leq 5 \mathrm{~mm}$ is from $10^{\circ} \mathrm{C}<T \leq 20^{\circ} \mathrm{C}$ to $20^{\circ} \mathrm{C}<T \leq 30^{\circ} \mathrm{C}$, the variation range of the average values of $\delta^{2} \mathrm{H}$ is $-55.94 \%$ to $-55.9 \%$, and the variation range of the average values of $\delta^{18} \mathrm{O}$ is $-6.76 \%$ to $-5.82 \%$. When $P>10 \mathrm{~mm}$, the temperature range is from $5^{\circ} \mathrm{C} \leq T \leq 20^{\circ} \mathrm{C}$ to $20^{\circ} \mathrm{C}<T \leq 30^{\circ} \mathrm{C}$, the variation range of the average values of $\delta^{2} \mathrm{H}$ is $-44.43 \%$ to $-5.2 \%$, and the variation range of the average values of $\delta^{18} \mathrm{O}$ is $-4.79 \%$ to $-1.09 \%$. At the same time, when $P \leq 5 \mathrm{~mm}$, the temperature increases by $10^{\circ} \mathrm{C}$, the variation range of the slope difference of the atmospheric precipitation line is $1.03-2.07$ and $0.6-1.59$, respectively. When $P>10 \mathrm{~mm}$ and the temperature rises by $15^{\circ} \mathrm{C}$, the slope difference of the MWL changes in the range of 0.37 and 0.39 . The results show that, with the increase of temperature, the greater the precipitation, the smaller the range of the MWL slope change.

3.4. Excess Deuterium. Dansgaard first defined the concept of $d$-excess: $d$-excess $=\delta^{2} \mathrm{H}-8 \delta^{18} \mathrm{O}$. The average value of $d$ excess in global precipitation is about $10 \%$, and the $d$-excess means the degree to which the stable isotope of local precipitation deviates from the GMWL due to the dynamic fractionation of isotopes in the process of vapor evaporation [28]; it can reflect that water evaporates to form the conditions of heat and moisture balance and reflect the precipitation formation of geographical environment and climatic conditions [29]. In the monsoon-affected areas of China, the winter wind is affected by dry continental air mass as well as atmospheric water vapor evaporation, the $d$ excess value is generally greater than $10 \%$, during the summer monsoon influenced by moist maritime air moisture, and the $d$-excess value is generally less than $10 \%$, reflecting that the rainfall from winter and summer monsoon clouds has different source areas [24]. The variation of $d$-excess in the Guanling area ranged from $-8.11 \%$ to $31.81 \%$, with an average of $13.08 \%$. In addition, there are also significant differences in the average $d$-excess values of the half-year precipitation in the winter and summer. The range of $d$-excess values in the summer half-year is $-8.11 \%$ 
TABLe 2: The $\delta^{2} \mathrm{H}-\delta^{18} \mathrm{O}$ correlation parameters for different precipitation levels in the Guanling region.

\begin{tabular}{|c|c|c|c|c|c|c|c|c|}
\hline $\begin{array}{l}\text { Precipitation } \\
\text { grades }\end{array}$ & $\begin{array}{l}\text { Temperature } \\
\text { class }\end{array}$ & $\begin{array}{l}\text { Sample } \\
\text { size }\end{array}$ & $\begin{array}{c}\delta^{2} \mathrm{H} \\
\text { average } \\
(\% \mathrm{o})\end{array}$ & $\begin{array}{c}\delta^{18} \mathrm{O} \\
\text { average } \\
(\% \text { ) }\end{array}$ & $\begin{array}{l}\text { Rainfall } \\
(\mathrm{mm})\end{array}$ & $\begin{array}{c}\text { The slope } \\
\text { of MWL } \\
(\%)\end{array}$ & $\begin{array}{l}\text { The intercept } \\
\text { of MWL (\%o) }\end{array}$ & $\begin{array}{l}\text { Correlation coefficient } \\
\text { (r) }\end{array}$ \\
\hline \multirow{3}{*}{$P \leq 1 \mathrm{~mm}$} & $1^{\circ} \mathrm{C} \leq T \leq 10^{\circ} \mathrm{C}$ & 7 & -2.29 & -3.27 & 4 & 11.09 & 33.97 & 0.859 \\
\hline & $10^{\circ} \mathrm{C}<T \leq 20^{\circ} \mathrm{C}$ & 8 & -11.49 & -3.62 & 4 & 9.02 & 21.19 & 0.971 \\
\hline & $20^{\circ} \mathrm{C}<T \leq 30^{\circ} \mathrm{C}$ & 17 & -67.39 & -9.44 & 7 & 7.99 & 7.99 & 0.993 \\
\hline \multirow{3}{*}{$1 \mathrm{~mm}<P \leq 5 \mathrm{~mm}$} & $1^{\circ} \mathrm{C} \leq T \leq 10^{\circ} \mathrm{C}$ & 7 & -18.4 & -5.67 & 19 & 9.36 & 29.04 & 0.979 \\
\hline & $10^{\circ} \mathrm{C}<T \leq 20^{\circ} \mathrm{C}$ & 10 & -17.51 & -3.45 & 25 & 7.77 & 14.1 & 0.987 \\
\hline & $20^{\circ} \mathrm{C}<T \leq 30^{\circ} \mathrm{C}$ & 11 & -73.45 & -10.21 & 19 & 8.37 & 11.99 & 0.976 \\
\hline \multirow{2}{*}{$5 \mathrm{~mm}<P \leq 10 \mathrm{~mm}$} & $5^{\circ} \mathrm{C} \leq T \leq 20^{\circ} \mathrm{C}$ & 5 & -48.48 & -7.63 & 47 & 8.5 & 16.39 & 0.997 \\
\hline & $20^{\circ} \mathrm{C}<\mathrm{T} \leq 30^{\circ} \mathrm{C}$ & 3 & -43.28 & -6.54 & 32 & 8.13 & 9.83 & 0.999 \\
\hline \multirow{2}{*}{$P>10 \mathrm{~mm}$} & $5^{\circ} \mathrm{C} \leq T \leq 20^{\circ} \mathrm{C}$ & 9 & -34.23 & -5.99 & 187 & 7.94 & 13.34 & 0.976 \\
\hline & $20^{\circ} \mathrm{C}<T \leq 30^{\circ} \mathrm{C}$ & 9 & -78.66 & -10.78 & 198 & 7.55 & 2.78 & 0.973 \\
\hline \multicolumn{2}{|c|}{ Total precipitation sample } & 86 & -43.92 & -7.13 & 542 & 8.81 & 18.91 & 0.975 \\
\hline
\end{tabular}

to $18.76 \%$, with an average value of $9.64 \%$. The range of $d$ excess values in the winter half-year is $11.32 \% 0-31.81 \%$, and the average $d$-excess values are up to $19.52 \%$. It indicated that the water vapor source in the Guanling area was not single, and the period affected by winter monsoon was longer than that of summer monsoon. The participation of local evaporating water vapor in water cycle was an important factor for the large deuterium surplus [22]. As can be seen from Figure 3, there are two regions where the $d$-excess values were unusually low or unusually high. Abnormally low area in summer half-year, the minimum value of $-8.11 \%$, according to the China meteorological data network monitoring results, are in the period of continuous precipitation during this period, the biggest precipitation is $41 \mathrm{~mm}$; the reasons may be high air humidity, maritime air mass in the process of water vapor transmission and weak imbalance fractionation. This keeps the deuterium surplus low from June to September. In winter half year, the highest value is $31.81 \%$, which may be due to the local evaporation of water vapor in the process of water vapor transport. When water body evaporates in unsaturated atmosphere, the ratio of ${ }_{2} \mathrm{H}$ to ${ }_{18} \mathrm{O}$ fractionation in evaporated water vapor is accelerated by the combined effect of light isotope preferential evaporation and dynamic fractionation, resulting in the increase of $\mathrm{d} \delta_{2} \mathrm{H} / \mathrm{d} \delta_{18} \mathrm{O}$ and d-excess in water vapor [11].

In atmospheric precipitation, the $d$-excess value is mainly related to meteorological conditions such as temperature, relative humidity, wind speed, water surface temperature, and roughness of the water body, among which temperature and humidity are the main factors that determine the evaporation of falling raindrops and the basic characteristic values that reflect atmospheric physical conditions and different water vapor sources [14]. The correlation between the $d$-excess value and the average daily temperature and precipitation was obtained by the least square method: $d$-excess $=-0.73 T+25.75$, $R^{2}=0.569, n=86 ; d$-excess $=-0.07 P+13.51, R^{2}=0.002$, $n=86$. There is a significant negative correlation between the $d$-excess value and the daily average temperature, while there is a very weak negative correlation between the $d$-excess value and the precipitation. That is, in the dry season, due to the transportation of water vapor in the westerly zone, the temperature is low, the relative humidity of the air is small, and the evaporation is fast. At the same time, it is mixed with part of the local evaporating water vapor to a large extent, resulting in relative enrichment of heavy isotopes and high $\mathrm{d}$-value. The rainy season comes from low latitude humidity. The replenishment of the ocean air masses is less affected by secondary evaporation under the clouds during the fall of raindrops. The temperature is high, the relative humidity is high, the evaporation is slow, the heavy isotopes are gradually leached and depleted, and the d-excess value is low.

3.5. Source Analysis of Water Vapor in Precipitation Events. In order to verify the source in the Guanling area, which indicates precipitation water vapor, the reliability of the six sets of stable hydrogen and oxygen isotope techniques representing precipitation events in the summer and winter half of the year were selected, respectively. The backward trajectory tracking module of HYSPLIT was used to track the water vapor source and migration path of each precipitation event. Three heights of 1,000, 2,500, and 3,000 m in the vertical direction were selected as the initial height of the simulation, which simulated the motion trajectory of the backward tracking for $166 \mathrm{~h}$. It can cover continuous precipitation events and improve the tracking precision of the water vapor source and transmission path.

Figures 4(a), 4(e), and 4(f) show the water vapor migration track results for three groups of precipitation events in the winter half-year. Figures 4(b)-4(d) show the water vapor migration path results for three groups of precipitation events in the summer half-year. As shown in the above study, the values of $\delta^{18} \mathrm{O}$ and $\delta^{2} \mathrm{H}$ vary greatly in winter and summer, which were usually lower in summer and higher in winter, mainly due to different water vapor sources and evaporation conditions. Meanwhile, the comparison of $d$-excess values indicated that $\delta^{18} \mathrm{O}$ and $\delta^{2} \mathrm{H}$ vary widely in winter and summer. The period of water vapor affected by winter monsoon is longer than the summer monsoon, and the local evaporative water vapor is an important factor for deuterium surplus. In winter, the 


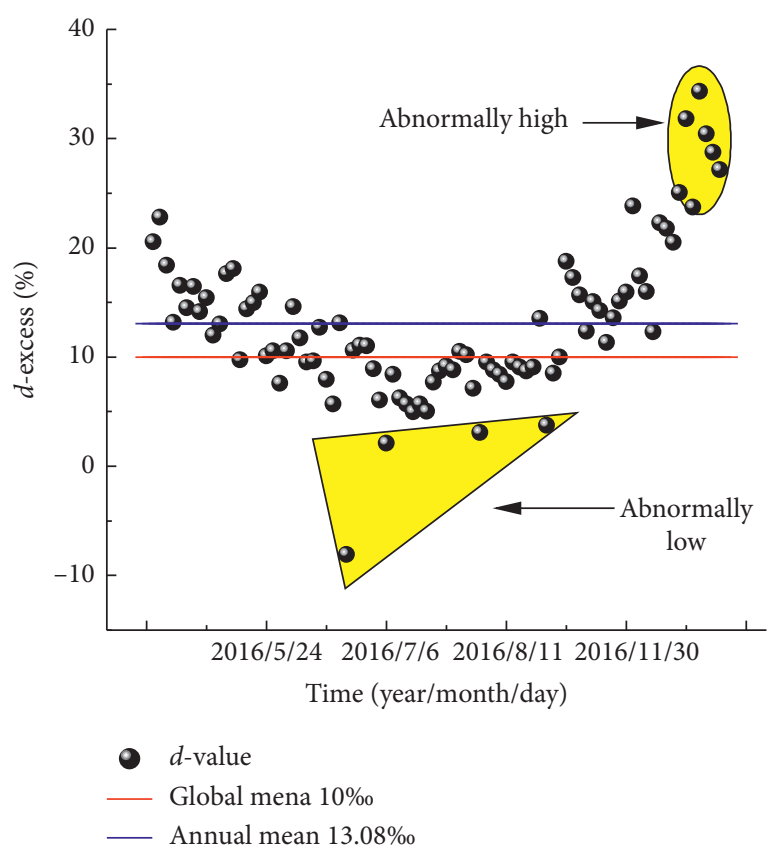

(a)

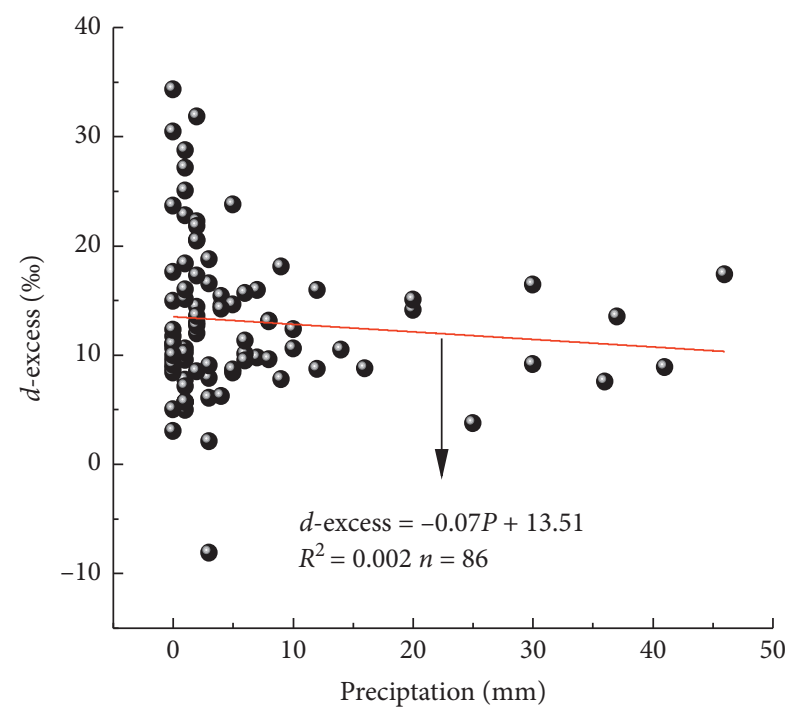

(c)

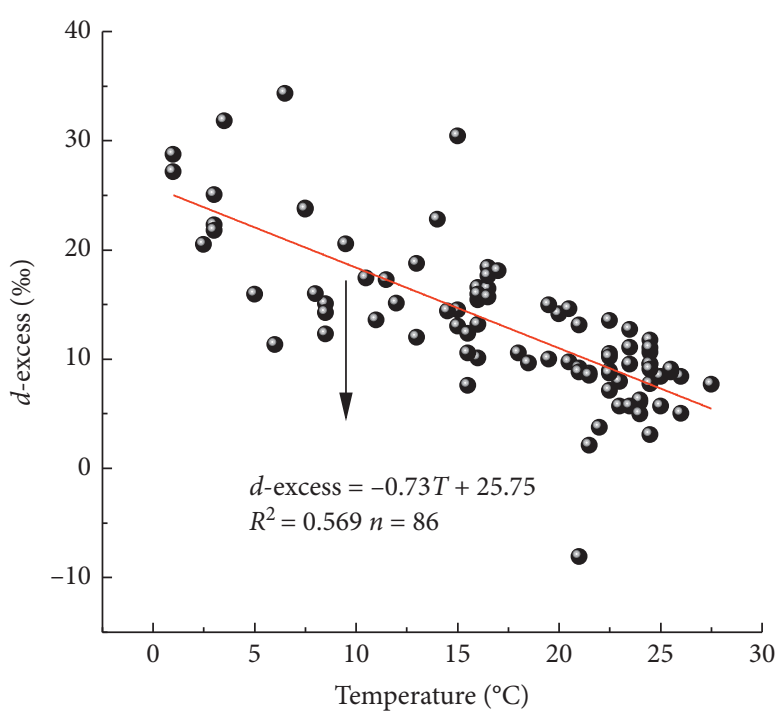

(b)

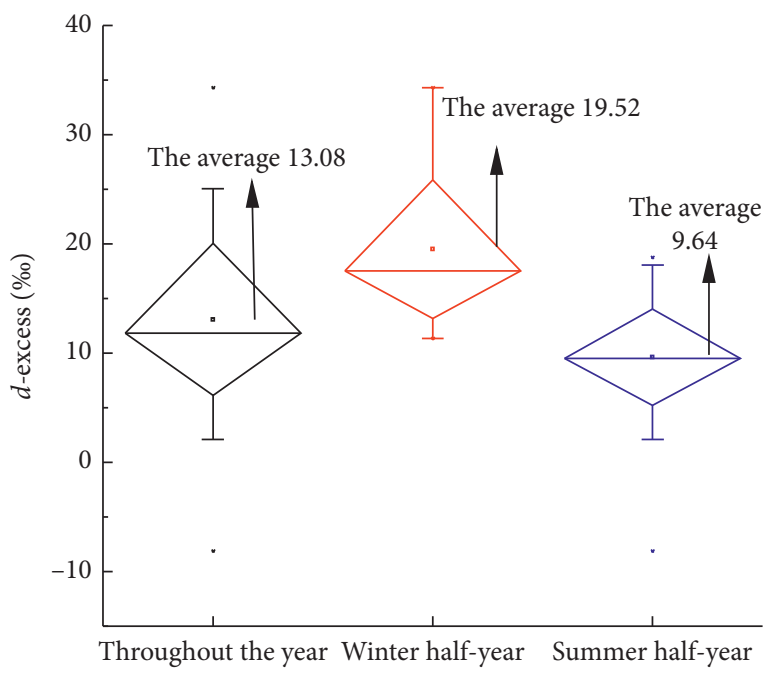

(d)

FIgURE 3: Variations of $d$-excess in precipitation in the Guanling region.

water vapor mainly comes from westerly transport, replenishment, and local reevaporation near the source sea. The simulation of the water vapor track of three groups of precipitation events shows that the near-source ocean water vapor and local reevaporation water vapor are dominant. Due to the migration path being shorter, the water vapor in the heavy isotopes experiences a "wash" function that is not strong, causing the heavy isotopes in the water vapor condensation to have priority for precipitation; $\delta^{2} \mathrm{H}$ and $\delta^{18} \mathrm{O}$ values as a whole are on the high side. The water vapor in the summer half-year mainly comes from the transport of water vapor from distant sources at low latitudes, such as the Arabian Sea, the Bay of
Bengal, the South China Sea, and the Western Pacific Ocean, and is also accompanied by local reevaporation. The long-distance transport of water vapor causes the heavy stable isotopes in the water vapor cluster to be continuously "washed," and the values of $\delta^{2} \mathrm{H}$ and $\delta^{18} \mathrm{O}$ are generally low. In addition, during the typhoon, the change of stable isotopes in precipitation presents unique characteristics. Typhoon No. 4, 2016, "Nida," landed on the coast of Dapeng street, Dapeng New District, Shenzhen, Guangdong Province, on August 2. The long-distance water vapor transport brought abundant precipitation to Guanling area, with continuous precipitation of $65 \mathrm{~mm}$, and heavy stable isotopes continuously being "washed" along the way, 


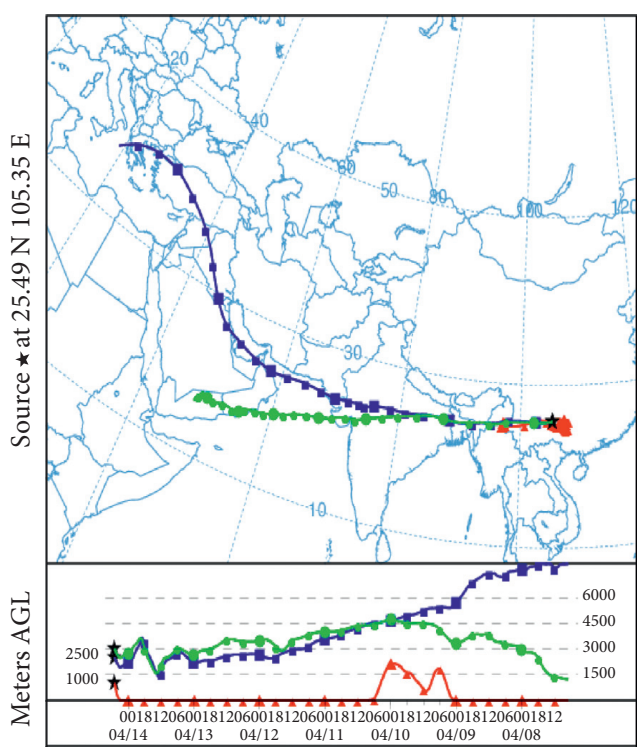

(a)

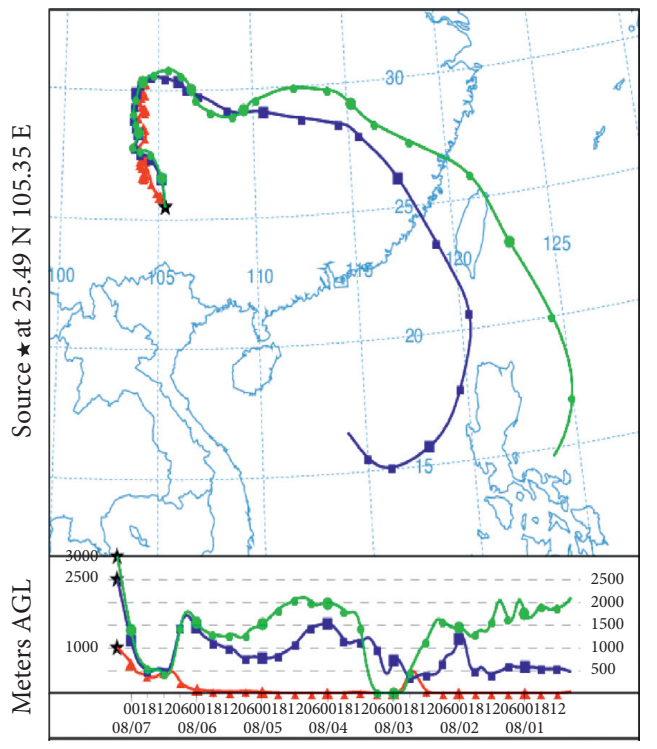

(c)

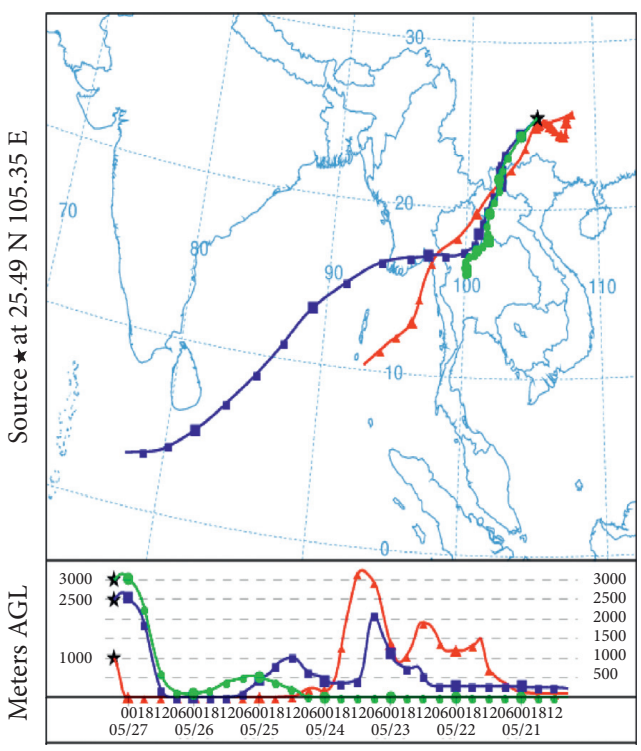

(b)

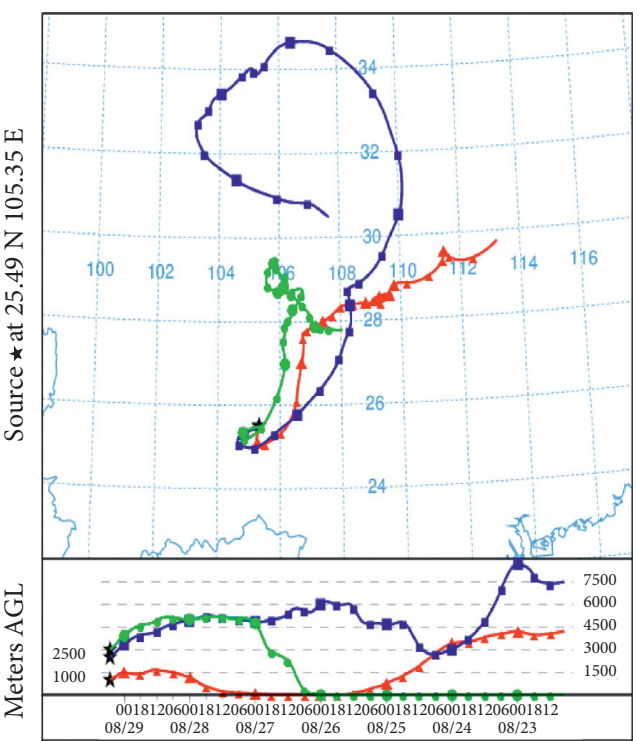

(d)

Figure 4: Continued. 


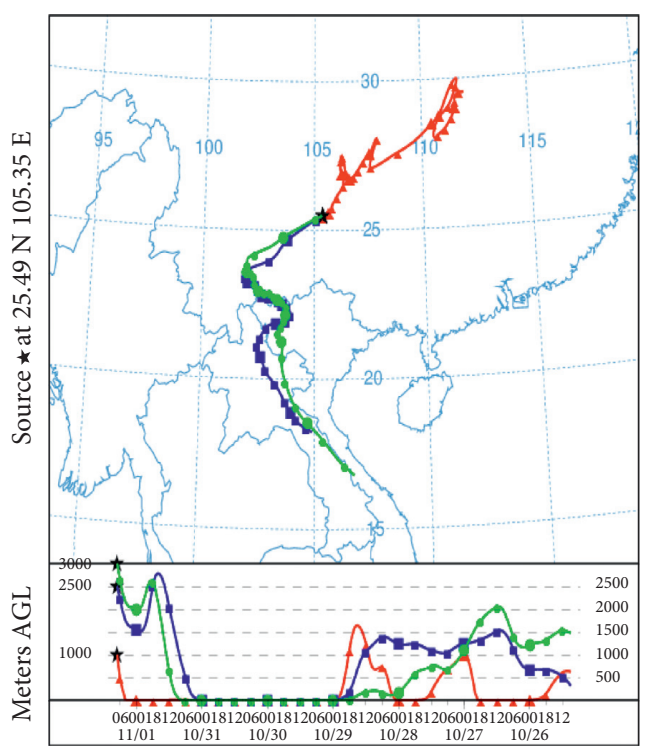

(e)

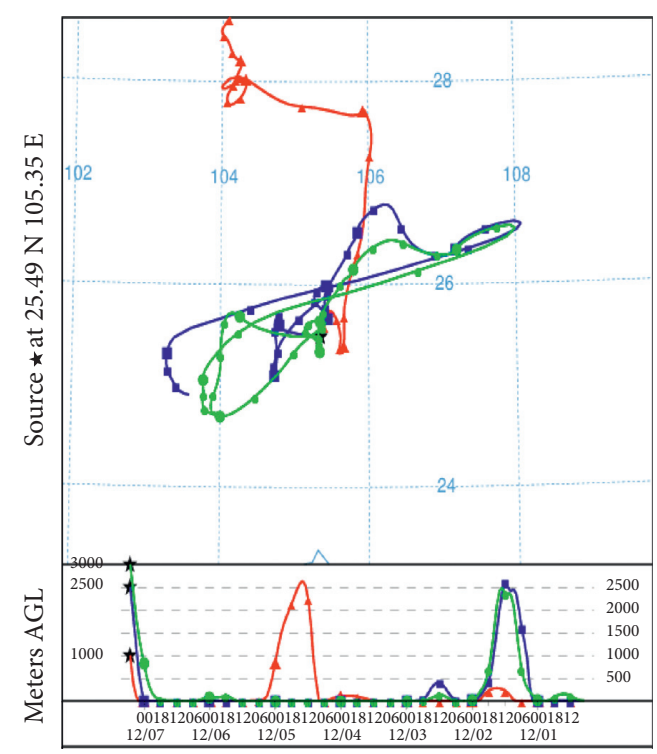

(f)

Figure 4: Backward trajectory of water vapor at different time in the Guanling region. (a) 2016-4-14. (b) 2016-5-27. (c) 2016-8-7. (d) 2016-829. (e) 2016-11-1. (f) 2016-12-7.

resulting in precipitation, $\delta^{2} \mathrm{H}$ and $\delta^{18} \mathrm{O}$ are at the lowest value of the whole year.

\section{Conclusion}

(1) The values of $\delta^{2} \mathrm{H}$ and $\delta^{18} \mathrm{O}$ in the precipitation in the study region are generally higher in the winter halfyear and lower in the summer half-year. The main reason is the seasonal difference in precipitation sources, moisture, and evaporation conditions. The $d$-excess average values of the half-year precipitation in winter and summer vary significantly. The higher average $d$-excess value of winter precipitation indicates that there is no single regional water source and it is affected by the winter monsoon which is longer than the summer monsoon period. The evaporation of atmospheric water vapor in the water cycle is an important factor in excess deuterium. At the same time, there is a significant negative correlation between the $d$-excess value and the daily average temperature.

(2) In the study area, the slope and intercept of the MWL equation $\left(\delta^{2} \mathrm{H}=8.81 \delta^{18} \mathrm{O}+18.91\right)$ are large, indicating that the climate in this area is warm and humid, and the secondary evaporation has a little influence on the precipitation process. Compared with the MWL in summer and winter half-year, the slope and intercept of the MWL in winter half-year are higher than those in summer half-year, which is related to the difference of dynamic fractionation process in summer and winter half-year caused by different water vapor sources. At the same time, the MWL in the winter half-year is close to the annual MWL, indicating that it is greatly affected by the sources of water vapor in the winter half-year in the Guanling area.

(3) The research results in the Guanling region show that the slope and intercept of the MWL decrease with the increase of rainfall level, and stable isotopes in precipitation are less affected by the secondary evaporation effect of the cloud bottom. The correlation between atmospheric precipitation $\delta^{18} \mathrm{O}$ and temperature and precipitation varies with different time scales. With the decrease of time scales, the correlation between atmospheric precipitation $\delta^{18} \mathrm{O}$ and temperature and precipitation is greater. At the same time, when $P \leq 5 \mathrm{~mm}$, the temperature is at $10^{\circ} \mathrm{C}<T \leq 30^{\circ} \mathrm{C}$, stable isotope change is the most sensitive, and with the increase of temperature, the greater the precipitation is, the smaller the change range of the slope of the MWL is.

(4) The water vapor in the winter half of the year mainly comes from the transportation of the westerly wind, the replenishment of water vapor near the source sea, and local reevaporation. The simulation of water vapor track of three groups of precipitation events shows that the near-source ocean water vapor and local reevaporating water vapor are dominant, which further proves that the participation of local evaporating water vapor in water circulation is a fundamental factor that leads to the greater $d$-excess in the winter half-year. In the half-year of summer, the water vapor mainly comes from the transport of water vapor from distant sources in low latitudes, such as the Arabian Sea, the Bay of Bengal, the South China Sea, and the Western Pacific Ocean, and is also accompanied by local reevaporation. During the 
influence of tropical cyclones, the values of $\delta^{2} \mathrm{H}$ and $\delta^{18} \mathrm{O}$ in precipitation are more negative.

\section{Data Availability}

The data used to support the findings of this study are available from the corresponding author upon request.

\section{Conflicts of Interest}

The authors declare that they have no conflicts of interest.

\section{Acknowledgments}

This study was financially supported by the Science and Technology Cooperation Project (LH[2017]7059 and LH[2016] 7282), the Academician Workstation of Science and Technology Plan (S\&T Cooperation Platform Talents [2016]5602), Project of National Key Research and Development Program of China in the 13th Five-year Plan (2016YFC0502606-01), and Project of Guizhou Normal University supporting Doctors Research (GZNUD[2017] no. 2).

\section{References}

[1] X. P. Zhang, J. M. Liu, M. Shi Nakawo, and Z. C. Xie, "Vapor origins revealed by deuterium excess in precipitation in southwest China," Journal of Glaciology and Geocryology, vol. 31, no. 4, pp. 613-619, 2009.

[2] H. W. Wu, X. P. Zhang, G. L. Sun, L. Shen, Y. M. Huang, and H. H. Wang, "Variations of $\delta^{18} \mathrm{O}$ in precipitation and moisture sources in the Yangtze river basin," Journal of Meteorology and Environment, vol. 27, no. 5, pp. 07-12, 2011.

[3] S. Zhang, W. X. Yu, Q. L. Zhang et al., "Distribution of deuterium and heavy oxygen in snow and ice water in mount Everest, southern Tibet, China," Science In China (Series A), vol. 1973, no. 4, pp. 430-433, 1973.

[4] J. R. Liu, X. F. Song, and G. F. Yuan, "Analysis of stable isotope characteristics of meteoric precipitation in China ecosystem research network," in Proceeding of the Theory and Practice of Human-Water Harmony: 4th Academic Symposium of China Water Forum, pp. 287-291, Beijing, China, August 2006.

[5] X. Duan, J. H. Ju, Z. N. Xiao, and B. Wang, Study on Physical Processes and Predictive Signals of Climatic Anomalies in Yunnan, Meteorological Press, Beijing, China, 2000.

[6] X. P. Zhang, J. M. Liu, W. Z. Sun, Y. M. Huang, and J. M. Zhang, "Study on the relationship between oxygen stable isotope ratio and related meteorological elements in precipitation in southwest China," Science in China Series D, vol. 36, no. 9, pp. 850-859, 2006.

[7] X. Y. Yang and Q. Liu, County Geographic Information and Economic Development in Guizhou, Guizhou People Press, Guiyang, China, 2004.

[8] W. Shen, X. Shu, J. L. Wang et al., "Variation characteristics of cave water hydrogeochemistry in Naduo cave of Guizhou and its implications for environment research," Environmental Science, vol. 36, no. 12, pp. 4455-4463, 2015.

[9] Y. R. Wen and J. L. Wang, "Variations of stable isotope in precipitation and its atmospheric circulation effect in chongqing," Environmental Science, vol. 37, no. 7, pp. 2462-2469, 2016.

[10] J. L. Wang, J. L. Wang, X. S. Jiang, Q. Y. Mao, and W. Shen, "Variation characteristics of cave drop water hydrogen and oxygen isotope in Naduo cave of Guizhou and its climatic implications," Yangtze River, vol. 47, no. 21, pp. 25-29, 2016.

[11] G. Li, X. P. Zhang, X. Z. Zhang, H. W. Wu, G. L. Sun, and Y. M. Huang, "Stable isotope characteristics of hydrogen and oxygen in meteoric precipitation in Tengchong, Yunnan," Resources and Environment in the Yangtze River Basin, vol. 22, no. 11, pp. 1458-1465, 2013.

[12] S. H. Zheng, F. H. Hou, and B. L. Ni, "Study on stable isotopes of hydrogen and oxygen in precipitation in China," Chinese Science Bulletin, vol. 28, no. 13, pp. 801-806, 1983.

[13] R. Wang, W. Z. Liu, and X. F. Song, "Analysis of hydrogen and oxygen isotope characteristics in atmospheric precipitation in Changwu plateau," Journal of Water and Soil Conservation, vol. 22, no. 3, pp. 56-59, 2008.

[14] K. Q. Wei and R. F. Lin, "On the influence of monsoon climate on the isotopic composition of rainwater in China," Geochemistry, vol. 23, no. 1, pp. 33-41, 1994.

[15] H. W. Wu, X. P. Zhang, H. D. Guan, G. L. Sun, Y. M. Huang, and T. T. Zhang, "Effects of different sources of water vapor on precipitation $\mathrm{D}$ and ${ }^{18} \mathrm{O}$ in Changsha, Hunan," Journal of Natural Resources, vol. 27, no. 8, pp. 1404-1414, 2012.

[16] H. Craig, "Isotopic variations in meteoric waters," Science, vol. 133, no. 3465, pp. 1702-1703, 1961.

[17] X. P. Zhang and T. D. Yao, "A study on the relationship between $\mathrm{D}$ and ${ }^{18} \mathrm{O}$ in modern precipitation in the northeast of qinghai-tibet plateau," Permafrost, vol. 18, no. 4, pp. 360365, 1996.

[18] C. L. Song, X. Y. Sun, and G. X. Wang, "Stable isotope characteristics of precipitation and source of water vapor in the subalpine region of Gongga mountain," Resources and Environment in the Yangtze River Basin, vol. 24, no. 11, pp. 1860-1809, 2015.

[19] X. P. Zhang and T. D. Yao, "Distribution characteristics of ${ }^{18} \mathrm{O}$ in precipitation in China," Journal of Geography, vol. 53, no. 4, pp. 356-364, 1998.

[20] Y. J. Shen and X. H. Peng, "Study on hydrogen and oxygen stable isotope characteristics in atmospheric precipitation in yingtan area," Journal of Ecology and Environment, vol. 23, no. 1, pp. 101-105, 2014.

[21] W. Dansgaard, "Stable isotopes in precipitation," Tellus, vol. 16, no. 4, pp. 436-468, 1964.

[22] L. Zhang, L. Cheng, J. Liu, F. L. Liu, and Z. Y. Chen, "D and ${ }^{18} \mathrm{O}$ isotopes of meteoric precipitation in Hong Kong," Journal of Ecology and Environment, vol. 18, no. 2, pp. 572-577, 2009.

[23] J. B. Xue, W. Zhong, and Y. J. Zhao, "The relationship between $\delta^{18} \mathrm{O}$ in Guangzhou's meteoric precipitation and meteorological elements and monsoon activities," Permafrost, vol. 30, no. 5, pp. 761-768, 2008.

[24] Y. Hao, X. X. Yu, W. P. Deng, G. D. Jia, Y. H. Lou, and Y. J. Bai, "The change of composition of $\mathrm{D}$ and ${ }^{18} \mathrm{O}$ in the precipitation of Xishan in Beijing and the source of water vapor," Journal of Natural Resources, vol. 31, no. 7, pp. 1211-1221, 2016.

[25] X. G. Jin, M. J. Zhang, S. J. Wang et al., "Secondary evaporation effect under loess plateau clouds based on stable hydrogen and oxygen isotopes," Environmental Science, vol. 36, no. 4, pp. 1241-1248, 2015.

[26] Y. C. Meng and G. D. Liu, "Secondary evaporation effect under clouds of stable isotopes of precipitation in the Yangtze river basin," Advances in Water Science, vol. 21, no. 3, pp. 327-334, 2010.

[27] S. K. Zhao, S. G. Pang, R. Wen, and Z. F. Liu, "Secondary evaporation effect of precipitation stable isotopes on cloud 
bottom in Haihe river basin," Advances in Geographic Sciences, vol. 34, no. 8, pp. 1031-1038, 2015.

[28] Z. X. Chen, J. Cheng, P. W. Guo, Z. Y. Lin, and F. Y. Zhang, "Distribution characters and its control factors of stable isotopein precipitation over China," Transaction on Atmospheric-Science, vol. 33, no. 6, pp. 667-679, 2010.

[29] D. J. Hou, X. Qin, J. K. Wu, and W. T. Du, "Characteristics of stable isotopes in precipitation and the water vapor sources in Urumqi," Journal of Arid Land Resources and Environment, vol. 25, no. 10, pp. 136-142, 2011. 